\title{
Statutes of limitations and personal identity
}

Christian Mott $^{1}$

Legal theorists have proposed several theories to justify statutes of limitations in the criminal law, but none of these normative theories is generally accepted. This paper investigates the related descriptive question as to whether ordinary people have the intuition that legal punishment becomes less appropriate as time passes from the date of the offense and, if they do, what factors play a role in these intuitions. Five studies demonstrate that there is an intuitive statute of limitations on both legal punishment and moral criticism, and that these intuitions arise, in part, from judgments about changes in psychological connectedness over time.

Statutes of limitations are ubiquitous in the criminal law. They provide that, for almost every crime, the state must commence a prosecution within a fixed period of time or lose the right to do so forever. Although these laws are common, they remain theoretically problematic, as there is no consensus about what legal end they achieve that makes them worth the cost of allowing guilty people to go free. ${ }^{2}$

Legal theorists have proposed a number of possible justifications for these laws. Some posit that it is practically and legally problematic to bring people to trial after a certain amount of time. Three prominent views are (1) that evidence degrades after a certain amount of time, and it is unfair to subject people to trials on degraded evidence; (2) that it is good for the legal system if the number of cases that can be prosecuted at any one time is bounded; and (3) that it is good for the police to have an incentive to complete their investigations within a specified amount of time, both to avoid delay and to prevent the police from spending too much time on any one case (Ochoa \& Wistrich, 1997; Powell, 2008; Robinson, 1982). Other justifications are based on the view that it is morally problematic to punish people after a certain amount of time has passed. Three prominent views of this sort are (4) that individuals simply have a right to be free of the threat of punishment after a certain amount of time (the right to repose), (5) that people reform over time, and so it is unnecessary and unfair to punish them after a certain amount of time

\footnotetext{
${ }^{1}$ I am grateful for comments on this paper from two anonymous reviewers, for encouragement and feedback from Josh Knobe, Shaun Nichols, Gideon Yaffe, Dan Bartels, Kevin Tobia, the members of the Yale University Experimental Philosophy Lab, and the attendees of the Interdisciplinary Conference on Personal Identity and Decision Making at the University of Chicago Booth School of Business, and for the generous support of the Oscar M. Ruebhausen Fund at Yale Law School.

${ }^{2}$ In actual practice, statutes of limitations must be asserted by defendants. If a defendant fails to do so, he or she may be convicted even if the statute of limitations period has run. Statutes of limitations are generally asserted in a pre-trial motion to dismiss the indictment or motions for a required finding of not guilty during trial. (For non-lawyers: This latter is a motion defendants generally make both when the prosecutor rests and when the defendant rests, which argues that the state has not presented sufficient evidence for a rational jury to find that all the elements of the crime have been proven beyond a reasonable doubt.) Accordingly, they may lead to the dismissal of an indictment before all the evidence has been presented or before the case has gone to the jury. Thus, the assertion of a statute of limitations defense often prevents there from being any adjudication of guilt, and may be used by the innocent as well as the guilty. While I highlight the downside here -statutes of limitations allow guilty people to go free - I should note that there is an obvious upside - they allow innocent people to avoid a trial. An assumption that the frequency of downside cases decreases over time while the frequency of upside cases increases over time may be part of a normative justification for statutes of limitations. As this paper is, ultimately, not aimed at finding normative justifications for statutes of limitations, this is the last I'll say on the matter.
} 
(Ochoa \& Wistrich, 1997; Powell, 2008; Robinson, 1982), or (6) that, after a certain amount of time, punishment no longer serves a deterrent function (Listokin, 2002). ${ }^{3}$

There is, ultimately, no consensus on which, if any, of these theories are correct. The most commonly mentioned ${ }^{4}$ are (1) degradation of evidence, (3) creating an incentive to investigate promptly, and (4) the right to repose. However, all three of these are open to convincing, though not decisive, counterarguments. As to (1), legal theorists have argued that it is the job of the rules of evidence to ensure that defendants are not convicted using degraded evidence, as they can be fine-tuned in ways that a blanket prohibition, like a statute of limitations, cannot. (Robinson 1982) As to (3), there is reason to think that police department pressures to clear cases provide the police with all the incentive they need to investigate quickly and to move on when investigations prove fruitless (Skolnick 2011). As to (4), positing a right to repose appears to locate the theoretical justification for statutes of limitations - it has something to do with the rights of criminal defendants - without explaining it in a satisfactory way.

\section{Statutes of Limitations and Psychological Connectedness}

The focus of this paper will be another proposed justification for statutes of limitations, due to Derek Parfit: that they are justified by the fact that people become less psychologically connected to their past selves as time passes. "When some convict is now less closely connected to himself at the time of his crime, he deserves less punishment. If the connections are very weak, he may deserve none. This claim seems plausible. It may give one of the reasons why we have Statutes of Limitations, fixing periods of time after which we cannot be punished for our crimes." (Parfit 1984: 326) This theory is a Parfitian take on an obvious point: the state ought not punish one person for the crimes of another. Parfit's thesis is that what matters in assessing whether punishment is appropriate is psychological connectedness, not personal identity. ${ }^{5}$

Parfit's understanding of psychological connectedness is broad. It includes direct memory connections, memory chains, continued holding of intentions, beliefs, desires, and other psychological features, and continuity of character. (Parfit 1984:205, 207) His concept of connectedness is graded, and can be measured in terms of the number of individual connections ${ }^{6}$ (e.g., individual memories, intentions, beliefs). When this number falls low enough-which can be caused by "a significant change of character, or style of life, or of beliefs and ideals" - it is correct to say that one is no longer the same person. (Parfit 1984:305)

The relevance of time to this theory of the relationship between moral responsibility and the connectedness of the self is due to the intuition that time affects the connectedness relationship. To spell it out, this relationship depends on two premises: (1) whether an individual $\mathrm{B}$ at time $t_{2}$ is morally responsible for an action, $\mathrm{N}$, taken by an individual $\mathrm{A}$ at time $\mathrm{t}_{1}$ depends on the degree to which B is psychologically connected to A, and (2) as the difference, $t_{2}-t_{1}$, increases, connectedness decreases. (Parfit 1984:305-306)

\footnotetext{
${ }^{3}$ It is worth nothing that amongst the moral justifications for the practice, one is external to any going theory of punishment (the right to repose) - that is, it requires the introduction of an additional right that gives a reason not to punish - while two are internal to one or another theory of punishment (rehabilitation and deterrence).

${ }^{4}$ Including, prominently, by the United States Supreme Court in United States v. Marion, 404 U.S. $307,322-323$ (1971).

${ }^{5}$ There may be a connection between a justification based on psychological connectedness and a justification based on rehabilitation. I discuss this possible connection in the descriptive context in the General Discussion.

${ }^{6}$ This method of counting connections applies less directly to changes of character, which arises out of these psychological features that are easier to count.
} 
Subsequent philosophers have developed the connectedness of the self model of personal identity, and have further considered its implications for moral responsibility. One author has agreed that psychological connectedness is relevant to moral responsibility, but has argued that the degree of connectedness necessary for responsibility is so low that, in general, a lower level of connectedness does not imply a lower level of responsibility. (Glannon 1998) Other authors have agreed more robustly with Parfit about the relevance of connectedness to responsibility, and have tried to flesh out the theory. On one view, the connections that matter for responsibility are those that "make up the motivational structure that brought about the act" (Khoury 2013), on another (tentative) view, they are causally connected "privileged subsets of the current and past agents' volitional webs." (Shoemaker 2012)

The present paper will not contribute to this normative debate. Rather, it will investigate a related descriptive question: whether ordinary people hold a roughly Parfitian view on the connection between psychological connectedness and moral and legal responsibility.

\section{The Psychological Question}

The ubiquity of statutes of limitations, and the difficulty theorists have had coming up with a coherent justification for them, suggests that one of the reasons they persist is not because of a particular end they are supposed to accomplish, but because they are psychologically intuitive. ${ }^{7}$ On this hypothesis, statutes of limitations track the intuitions ordinary people have about when, and to what extent, criminal punishment is appropriate. ${ }^{8}$ If this is the case, we may, without resolving the normative debate, inquire into whether these intuitions exist and whether they appear to follow any descriptive rules.

In looking for rules that describe and predict intuitions about statutes of limitations, an obvious place to start is with the normative theories discussed above. That is, we can take a normative theory, like the theory that the state ought not to punish for a crime any individual who is not sufficiently psychologically connected to the person who committed the crime, and hypothesize that ordinary people's intuitions follow this rule. That is, we may hypothesize that ordinary people only think that an individual should not be punished for a crime after $\mathrm{X}$ years because they also think that after $\mathrm{X}$ years she ceases to be sufficiently connected to the person who committed the crime.

Recent research suggests that if statutes of limitations are intuitive, this descriptive analogue of Parfit's theory is a particularly promising candidate rule (henceforth, this descriptive analogue will be called the "Parfitian hypothesis"). In the last few years, researchers have discovered that manipulating participants' judgments about how connected their present selves are to their future selves or past selves can affect their judgments about reward and punishment. Bartels, Kvaran, and Nichols (2013) found that manipulating participants' judgments about the connectedness of self over time - by directly informing them either that the characteristics that make them who they are change significantly after college graduation or are fixed at the end of

\footnotetext{
${ }^{7}$ A reviewer made the helpful point that there are historical explanations as to why some particular statutes of limitations came into existence, some of which are related to the existence of statutes of limitations in the civil law. I do not mean to be offering a historical account of why any particular statutes of limitations exist. Rather, I intend only to investigate whether one possible reason they remain pervasive in the criminal law is that they match up with ordinary intuitions about moral responsibility and legal punishment.

${ }^{8}$ People might also have intuitions about when it is appropriate to pursue criminal investigations, seek indictments from a grand jury, or file criminal complaints. That is, they may have time-related intuitions that are not based on when punishment is appropriate. I do not pursue these possibilities in this paper, except insofar as participants may view being subject to the legal process as a form of punishment.
} 
adolescence - can affect how willing participants are to wait for a reward. Tierney, Howard, Kumar, Kvaran, and Nichols (2014) then found that this same explicit manipulation can reduce participants' judgments of how much they themselves deserve punishment for their actions as recently as one year ago.

Other psychological research on the self is difficult to reconcile with this hypothesis, however. Tobia (2015) found that ordinary judgments as to whether a physically continuous individual who changed over time was identical to a past self depended on the direction of change. Across two different studies, his participants agreed more strongly that an individual who experienced a sharp psychological discontinuity remained identical to his pre-change self when the change was for the better than when it was for the worse. ${ }^{9}$ Most relevant here, one of these examples (the Nineteenth Century Russian) involved change in character over time. While these studies involved judgments of personal identity rather than psychological connectedness, it is intuitive to think that these judgments would be tied together. If they are, then Tobia's results seem to predict that ordinary judgments would differ from the Parfitian hypothesis. Faced with a description of an individual who is physically continuous with someone who committed an earlier crime, one would expect participants to infer that this person has improved over time, and that therefore the personal identity relation still holds between him and his crime-committing self. The differences between Tobia's studies and Parfit's theory leaves room for both to be true, however, particularly if participants agree with Parfit's fundamental thesis that personal identity is not what matters to moral responsibility. ${ }^{10}$

In light of this research, this paper has two aims: (1) to determine if statutes of limitations are intuitive and (2) to investigate whether these intuitions are based, at least in part, on other intuitions about the connectedness of the self over time.

\section{The Present Studies}

The present studies demonstrate that people think that wrongdoers become less deserving of both moral criticism and legal punishment as time passes. This finding indicates that statute of limitations intuitions are driven, at least in part, by factors common to the moral and legal contexts (as in (4)-(6) above) rather than factors that are particularly legal (as in (1)-(3) above). ${ }^{11}$ Thus, while the studies focus, in particular, on investigating intuitions about connectedness of the self over time, they also investigate whether intuitions about deterrence, the right to repose, and rehabilitation may play some role.

One feature of all these studies merits some initial discussion. The studies use a connectedness measure that asks participants to make a judgment about "the degree of connectedness between the person [someone] was when he [committed the crime] and the person he is when [he is subject to legal punishment or moral criticism]." This measure leaves the concept of connectedness somewhat vague, so that it could encompass all the elements Parfit suggested might play a role in it: memories, beliefs, desires, intentions, and character. In this respect, the present study differs from both the study by Bartels, Kvaran, and Nichols (2013) and the study by Tierney, Howard, Kumar, Kvaran, and Nichols (2014). Each of those studies directly manipulated judgments of connectedness by telling participants theories about the effect

\footnotetext{
${ }^{9}$ In both of Tobia's studies, the averages for both conditions fell on the identity side the midpoint of his scale, indicating that, on average, participants believed that the changes described in his study were identity-preserving.

${ }^{10}$ Note that this hypothesis may be consistent with Tobia's suggestion that numerical and legal identity might come apart such that legal identity does not depend on the direction of change while numerical identity does.

${ }^{11}$ The findings do not rule out the possibility that this particularly legal factors play a role in the legal intuitions.
} 
of college on a person's "core identity" and "characteristics that make [someone] the person [they] are." Such an approach has the definite advantage of ensuring that participants are thinking in terms of identity. But it also risks ruling out certain features that philosophers have thought may be important to psychological connectedness, such as memory. By contrast, the measure used in the present studies allows participants to give content to the concept of connectedness over time without explicitly suggesting that this concept relates to personal identity.

Study 1 shows that the effect of time on judgments about the appropriateness of legal punishment is mediated both by judgments about the connectedness of the self over time and judgments about the right of repose, but not by judgments about deterrence. Study 2 shows that the effect of time on judgments about the appropriateness of moral criticism for a past act is mediated both by connectedness judgments and deterrence judgments. Study 3 shows that another way of manipulating connectedness judgments - not using time as an independent variable - significantly affects moral criticism judgments. Study 4 shows the same for legal punishment judgments. Study 5 replicates Study 4 and controls for the possibility that participants inferred rehabilitation over time.

\section{Study 1. Legal punishment intuitions over time.}

Study 1 demonstrates, first, that in at least one case ordinary people think that legal punishment becomes less appropriate as time passes, and second, that this effect is mediated by judgments about connectedness over time. The study tests three proposed mediators: connectedness, the right of repose, and deterrence. ${ }^{12}$ It finds significant mediation by the first two but not the last one.

\section{Procedure}

Two hundred seventy-five participants were recruited using Amazon's Mechanical Turk. They were randomly assigned to receive one of ten versions of the following vignette:

John often goes to bars at night, but he always waits until he is sober to drive home.

One night, however, he drinks more than usual and tries to drive his car home while impaired. He is unable to keep the car straight and ends up weaving into the other side of the street. However, he manages to get the car home without hitting anything.

The next day [three years later; six years later; ... ; thirty years later], the police find a security camera video showing John's action and are able to identify him with $100 \%$ accuracy. They arrest him and turn the video over to the local district attorney.

Participants were then asked to respond to the following question on a scale from 1 (completely disagree) to 7 (completely agree):

Please indicate the extent to which you agree or disagree with the following statement:

\footnotetext{
${ }^{12}$ Rehabilitation was not used as a mediator in the first three experiments out of concern that a question about rehabilitation would be similar enough to a question about connectedness that it might affect participants' answers. Study 5 attempts to rule out judgments about rehabilitation as an explanation for the effect. Further discussion of the relation between rehabilitation and connectedness appears in the General Discussion.
} 
Once the video tape is found the next day, it is right for John to be arrested and punished.

Participants then received three proposed mediators in counterbalanced order: a connectedness mediator, a deterrence mediator, and a right of repose mediator. Responses to the connectedness mediator (adapted from Bartels et al., 2013) were given on a seven-point scale from "completely disconnected" to "completely connected":

Please indicate your opinion about the degree of connectedness between the person John was when he drank and drove and the person he is when the police find the video the next day [three years later; six years later; ... ; thirty years later] by selecting an option below, where no overlap means "completely disconnected" and complete overlap means "completely connected."
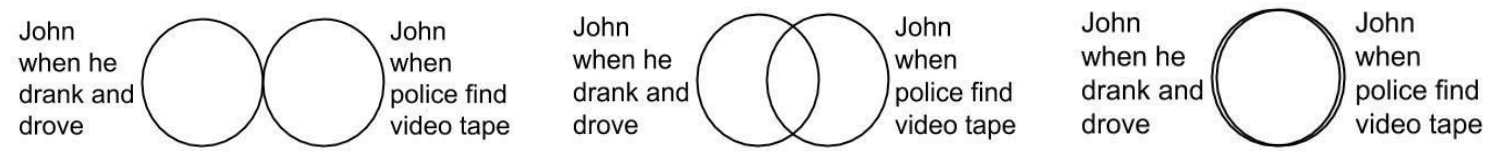

Responses to the deterrence mediator were given on a seven-point scale from "completely disagree" to "completely agree":

Please indicate the extent to which you agree or disagree with the following statement:

If John had known that he was going to be arrested and punished the next day [three years later; six years later; ... ; thirty years later], he would have been less likely to drive drunk.

As were responses to the right of repose mediator:

Please indicate the extent to which you agree or disagree with the following statement:

After one day [three years; six years; ... ; thirty years], John has the right to be able to stop worrying about being arrested and punished.

\section{Results}

The mean responses to the question asking for legal punishment intuitions are plotted in Figure 10.1: 


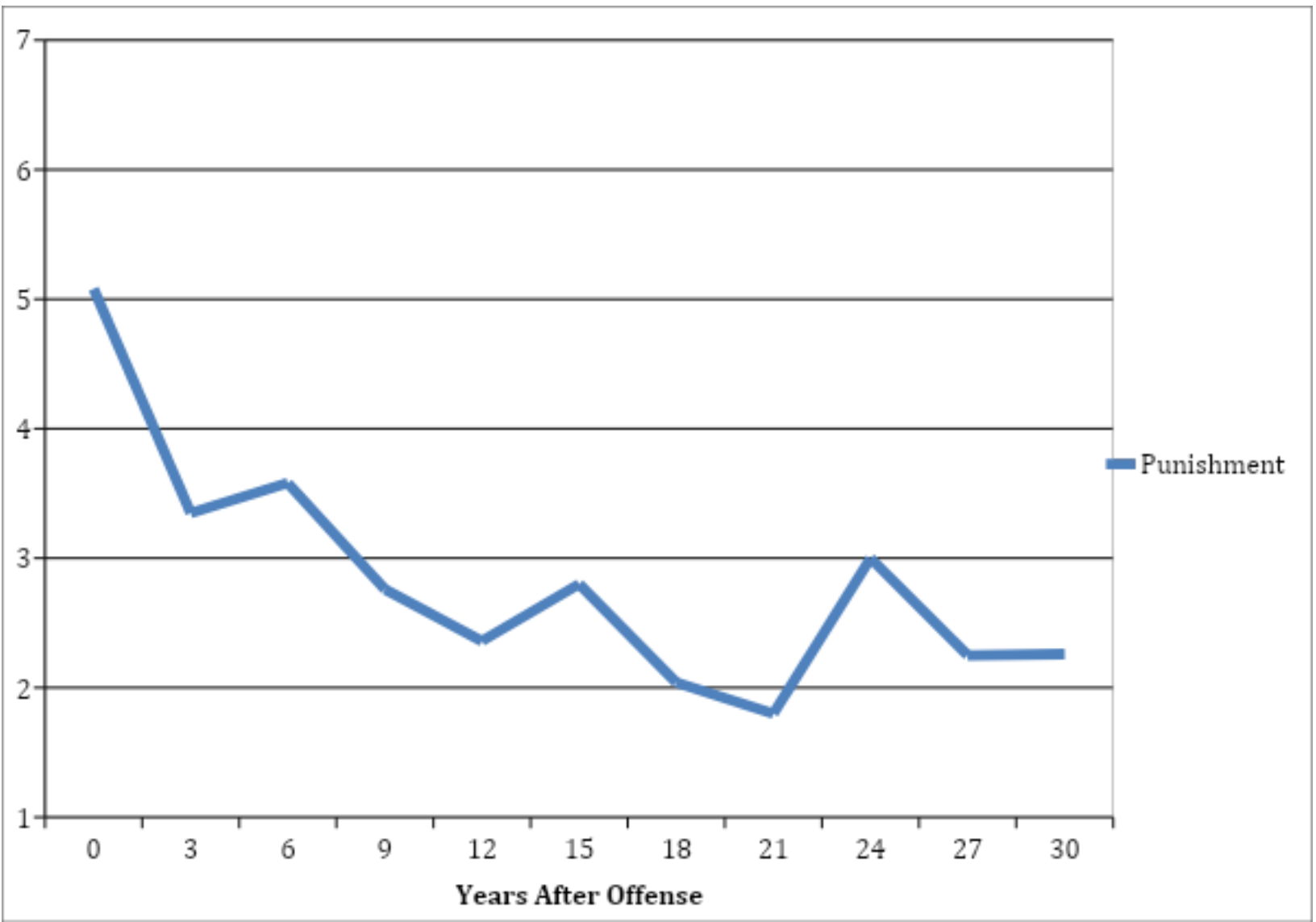

Figure 10.1. Mean legal punishment judgments over time in Study $1 .^{13}$

A regression showed that time had a significant effect on punishment judgments, $\beta=-0.32, p<$ .001 . Time also had a significant effect on connectedness judgments, $\beta=-0.3, p<.001$, and judgments about the right of repose, $\beta=-0.3, p<.001$, but did not have a significant effect on deterrence judgments, $\beta=-0.09, p=.13$. A regression using time, connectedness, right of repose, and deterrence to predict punishment showed significant effects of connectedness, $\beta=0.19, p<$ .001 , and right of repose. $\beta=-0.68, p<.001$, but not of time, $\beta=-0.06, p=.12$, or deterrence, $\beta$ $=0.04, p=.26$.

A bootstrap multiple mediation analysis (Hayes, 2013) showed significant indirect effects of time on legal punishment judgments through connectedness judgments $(95 \% \mathrm{CIs}$ $[-0.02,-0.01])$ and through right of repose judgments $(95 \%$ CIs $[-0.06,-0.02])$ but not through deterrence judgments $\left(95 \%\right.$ CIs [-0.004,0.001]) (see Figure 10.2). ${ }^{14}$

\footnotetext{
${ }^{13} \mathrm{~A}$ t-test reveals that the spike between 21 years and 24 years is significant; $p<0.05$. It is accompanied by a significant decrease in agreement with the statement that John had a right to be able to stop worrying; $p<0.05$. Given the large number of conditions, I expect that this significant effect is type 1 error.

${ }^{14}$ Note that the small unstandardized coefficients of the effect of years on the other variables in Figure 10.2 is due in part to the fact that the listed coefficient is for the effect of each individual year, not each interval of three years.
} 


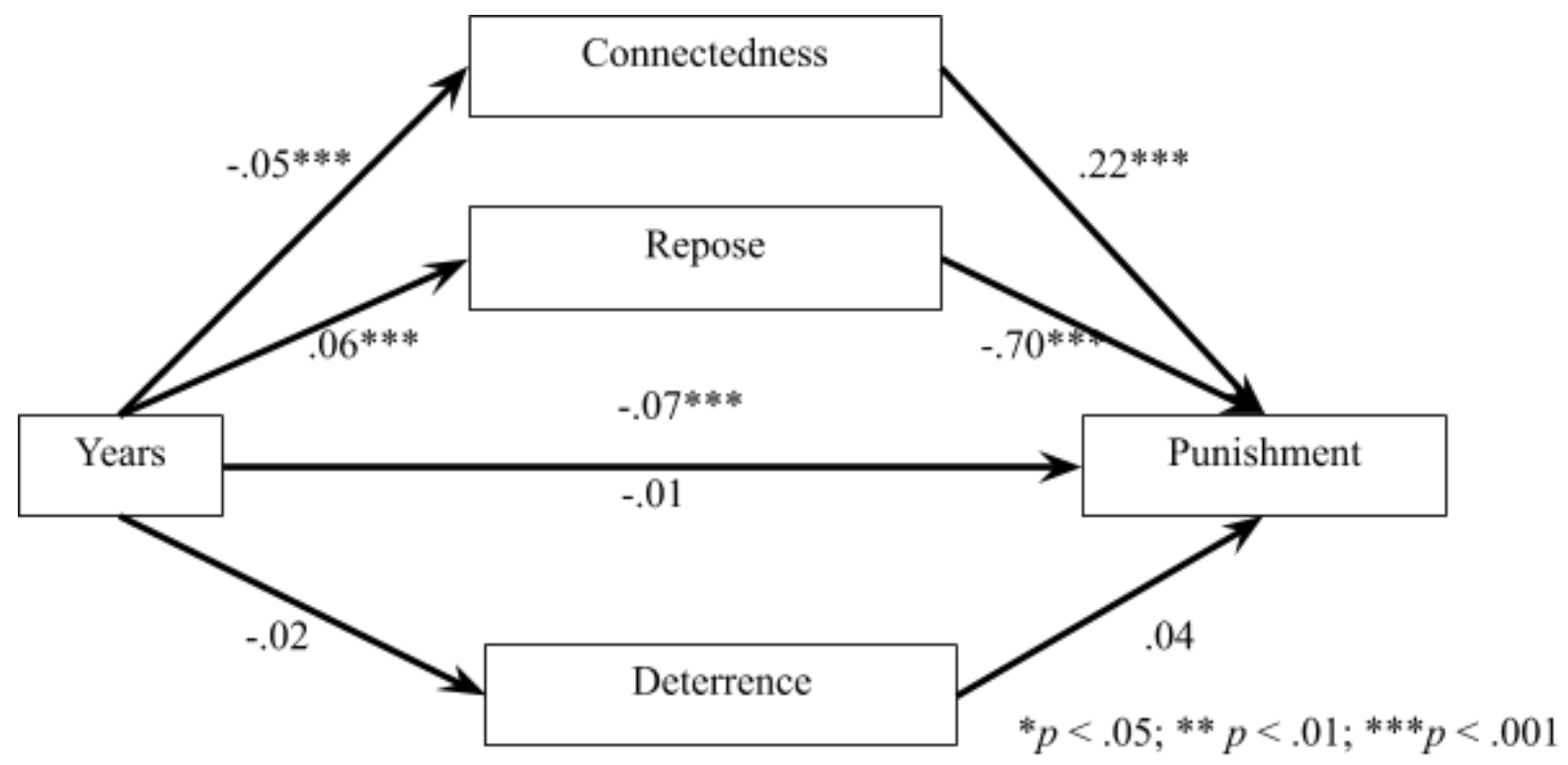

Figure 10.2. Full mediation of legal punishment judgments by both connectedness judgments and deterrence judgments in Study 1.

\section{Discussion.}

These results support the Parfitian hypothesis in two ways. First, they show that ordinary people do think that a person becomes less deserving of legal punishment for a crime as time passes after the commission of the crime. Two, they show that this effect is driven, at least in part, by judgments about how connected the earlier person is to the later person. The results also support one justification for statutes of limitations that are popular in the legal literature: the right to repose. ${ }^{15}$

This study did not test a number of the traditional legal justifications for statutes of limitations, however, such the degradation of evidence and the need to give the police an incentive to investigate quickly. The next study shows that even if these types of justifications play some role in ordinary intuitions, they cannot be driving the whole effect, which appears even when participants are asked about the appropriateness of moral criticism rather than legal punishment.

\section{Study 2. Moral criticism intuitions over time}

Study 2 investigated whether the same pattern from Study 1 holds for moral criticism rather than legal punishment. In this study, the only proposed mediator tested was deterrence. ${ }^{16}$

\section{Procedure}

\footnotetext{
${ }^{15}$ A reviewer noted that the phrasing of the right to repose mediator is such that participants could have thought the word "right" referred to a legal right. That is, they could have thought this question was asking them a legal question about how long the statute of limitations is for the crime described. This alternative explanation is certainly available, depending on one's reading of the mediator and one's assessment of the probability that participants knew about the statutes of limitations in question.

${ }^{16}$ The right of repose mediator was not included. While a moral right similar to the right to repose may exist, we were concerned that this mediator would make participants think too closely about the legal question investigated in Study 1. Since the primary purpose of this investigation is to build the positive case for the importance of connectedness, rather than prove that other factors do not play a role, we decided not to include this question.
} 
Two hundred seventy-seven participants were recruited using Amazon's Mechanical Turk. They were randomly assigned to receive one of ten versions of a vignette almost identical to the vignette used in Study 1, except that the last paragraph was changed to read:

The next day [three years later; six years later; ... ; thirty years later], John's good friend Alex finds out what he did. Alex criticizes John severely for his action, saying that he should feel ashamed of himself.

Participants were then asked to respond to the following question on a scale from 1 (completely disagree) to 7 (completely agree):

Please indicate the extent to which you agree or disagree with the following statement:

Alex was right to criticize John in this way.

Participants then received the two proposed mediators in counterbalanced order. Responses to the connectedness mediator (adapted from Bartels et al., 2013) were given on a seven-point scale from "completely disconnected" to "completely connected":

Please indicate your opinion about the degree of connectedness between the person John was when he drank and drove and the person he is when Alex criticizes him by selecting an option below, where no overlap means "completely disconnected" and complete overlap means "completely connected."

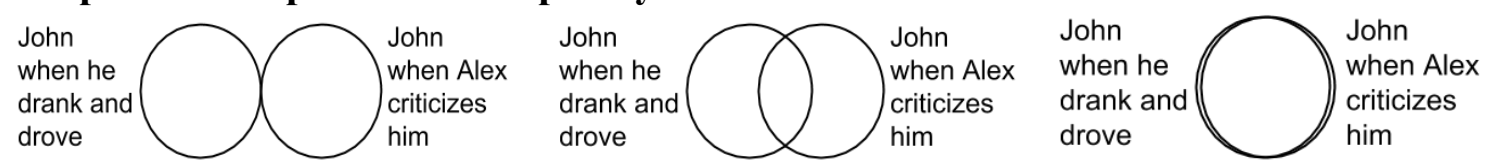

Responses to the deterrence mediator were given on a seven-point scale from "completely disagree" to "completely agree":

Please indicate the extent to which you agree or disagree with the following statement:

If John had known that Alex was going to criticize him the next day [three years later; six years later; ... ; thirty years later], he would have been less likely to drive drunk.

The mean responses to the question asking for moral criticism judgments are plotted in Figure 10.3: 


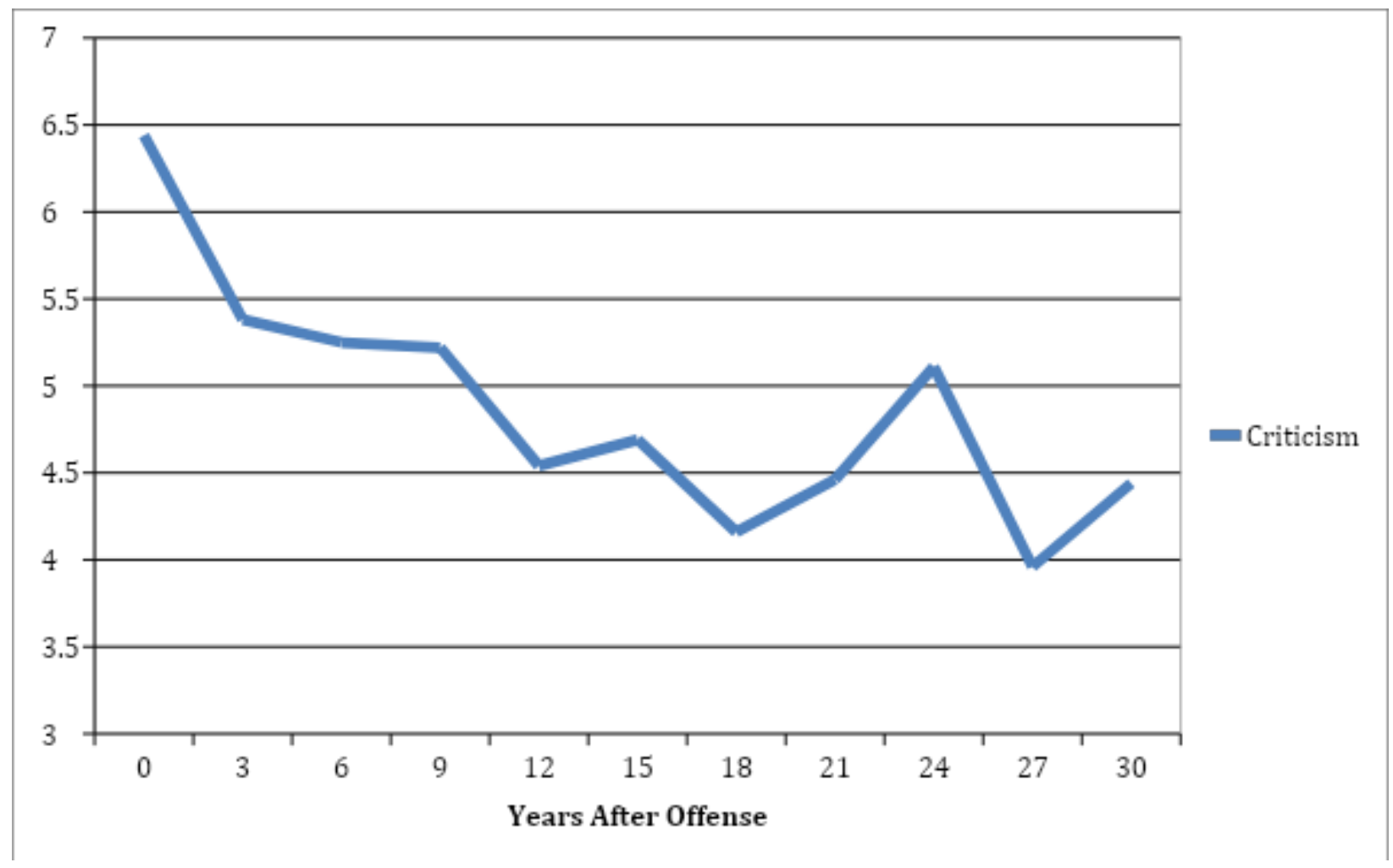

Figure 10.3 Mean moral criticism judgments over time in Study $2 .{ }^{17}$

A regression using time to predict criticism judgments showed a significant effect, $\beta=-0.27, p<$ .001 . Another regression showed a significant effect of connectedness judgments, $\beta=0.27, p<$ .001 , deterrence judgments, $\beta=0.27, p<.001$, and time, $\beta=-0.19, p<.001$, on criticism judgments. A bootstrap mediational analysis (Hayes, 2013) showed significant indirect effects of time on moral criticism judgments through connectedness judgments $(95 \%$ CIs [-0.02,-0.003]) and through deterrence judgments $(95 \%$ CIs $[-0.01,-0.001])$ (see Figure 10.4). ${ }^{18}$

\footnotetext{
${ }^{17}$ A t-test showed that the apparent spike between 21 years and 24 years is not significant; $p=0.26$. It is likely due to the fact that the average sample size for each condition was around 28.

${ }^{18}$ Note that the small coefficients on the effect of years in Figure 10.4 is due in part to the fact that the listed coefficient is for the effect of each individual year, not each interval of three years.
} 


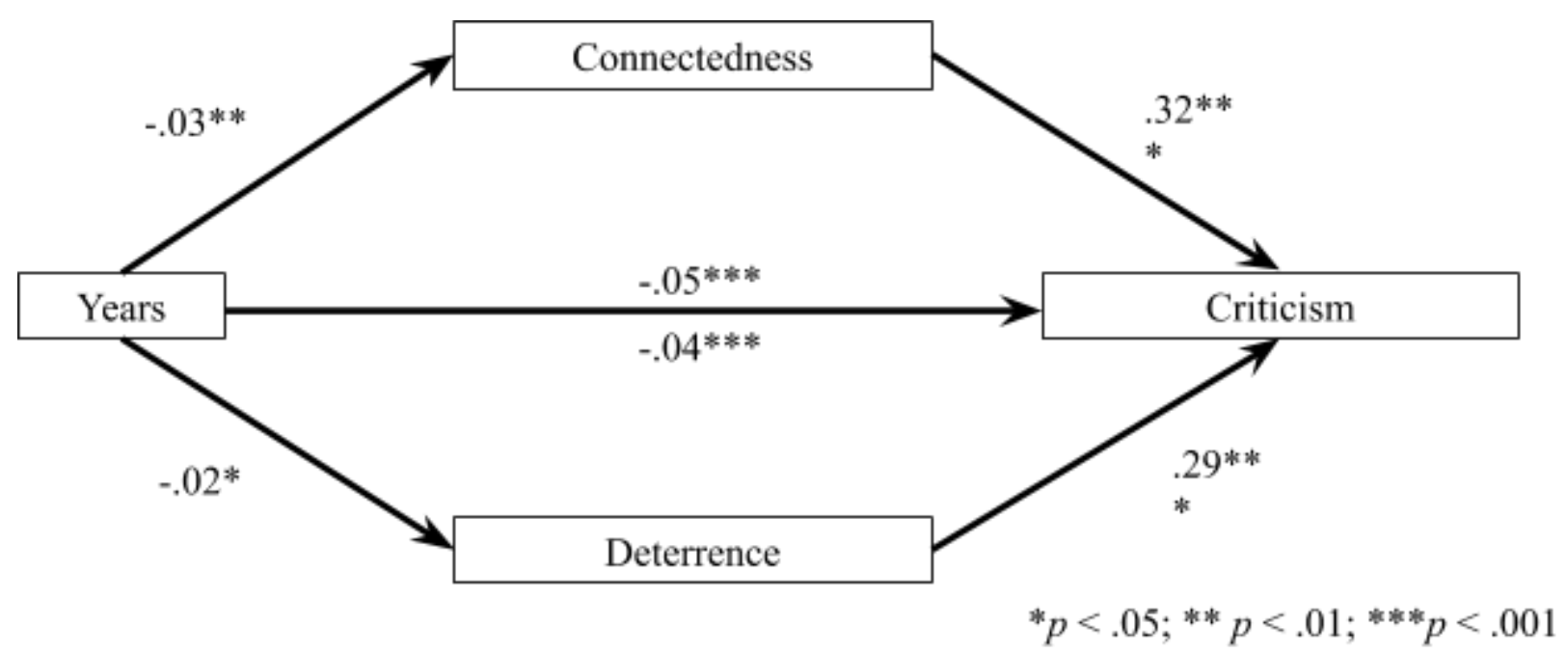

Figure 10.4 Partial mediation of moral criticism judgments by both connectedness judgments and deterrence judgments in Study 2.

\section{Discussion.}

These results provide even more support for the Parfitian hypothesis, which rests implicitly on the assumption that judgments of moral responsibility and legal punishment are linked. First, they show a similar pattern in judgments about the appropriateness of moral criticism as appeared in judgments about the rightness of legal punishment. Second, they show that the effect of time on moral judgments, like the effect on legal judgments, is mediated by judgments about connectedness.

One potentially interesting result of this study that is not directly related to the main question investigated in this paper is that deterrence did mediate the effect of time on judgments of moral criticism, while it did not mediate the effect of time on judgments of legal punishment in Study 1. As a reviewer pointed out, this inconsistency is counterintuitive. One would expect that, if anything, deterrence would play a role in legal judgments but not in moral judgments. One possible explanation for this inconsistency is omitted variable bias. In Study 1, participants were asked about the right to repose as well, while in Study 2 they were not. However, this explanation can be ruled out. The order in which the participants viewed the repose and deterrence mediators in Study 1 had no significant effect on their answers to either question. ${ }^{19}$ A regression using years, deterrence, connectedness, and repose to predict punishment judgments based solely on the data from Study 1 for participants who saw the deterrence mediator before the right to repose mediator indicates that deterrence still did not have a significant effect. ${ }^{20}$

\section{Study 3. Manipulation of connectedness judgments affects moral criticism judgments}

Studies 1 and 2 demonstrated that participants thought that both legal punishment and moral criticism became less appropriate as time passed from the date of the offense, and that connectedness judgments mediated the effect of time. However, these two studies produced inconsistent results as to what other judgments mediated the effect - the right of repose in Study 1 and deterrence in Study 2 - and thus indicated that the passage of time affects a number of intuitions that may be difficult to catalogue or disambiguate.

\footnotetext{
${ }^{19}$ Based on t-tests. For deterrence, $p=0.996$, and for repose, $p=0.309$.

${ }^{20}$ Analyzing data from the 135 participants who saw the deterrence mediator first, $\beta=0.07, p=0.16$.
} 
Thus, in Study 3, participants' connectedness judgments were manipulated non-temporally while time was held fixed. The connectedness manipulation used here is the reverse of that used by Bartels and colleagues (2013) and Tierney and colleagues (2014). Rather than attempting to alter participants' beliefs about how much people generally change over time, this study presents participants with a vignette either describing a person changing or staying the same and elicits judgments of connectedness based on participants' preexisting beliefs. The goal was to describe a change that did not constitute a clear moral improvement or degradation, however this assumption was not tested in this original study. ${ }^{21}$

\section{Procedure}

Two hundred forty-five participants were recruited using Amazon's Mechanical Turk.

Participants received one of four vignettes describing a person who was either a jock or a punk at the start of college, when he committed a minor crime (shoplifting an mp3 player). By the end of college, that person had either changed into the other type of person (that is, the jock had become the punk or the punk had become the jock) or had remained the same. In all cases, participants were then told that the individual's crime was discovered by a friend four years after graduation, and the friend criticized him for it. As an example, this is the punk-jock vignette:

When John starts college, he wears torn, black clothing, has several piercings and tattoos, and often wears his hair in a mohawk. He spends most of his free time at loud punk concerts in basements and other small venues. He plays guitar in a band. His songs feature piercing guitars, screamed vocals, and lyrics about resisting figures of authority.

During his first year of college, John doesn't have very much money but he really wants a new mp3 player. He ends up shoplifting an mp3 player from a local electronics store.

Once he graduates from college, John has changed significantly. He no longer has piercings, and he wears clothes that cover up his tattoos. He never wears his hair in a mohawk or goes to punk concerts. In college, he joined a fraternity and spent most of his free time going to parties to meet sorority girls. By the time he was a senior, he played on the varsity football team. He wears his letter jacket everywhere and enjoys watching sports, talking about sports, and working out.

Four years after graduation, John is the same as he was at the end of college. Whenever he can, he gets together with his fraternity brothers to play pick up football. At that time, his friend Alex finds out that John shoplifted an mp3 player when he was a freshman in college. Alex criticizes John severely for his action, and says that he should be ashamed of himself.

And this is the punk-punk vignette:

When John starts college, he wears torn, black clothing, has several piercings and tattoos, and often wears his hair in a mohawk. He spends most of his free time at loud punk

\footnotetext{
${ }^{21}$ Study 5 indicates that while participants did view the change as having a valence, their assessment of that valence did not mediate the effect on connectedness judgment.
} 
concerts in basements and other small venues. He plays guitar in a band. His songs feature piercing guitars, screamed vocals, and lyrics about resisting figures of authority.

During his first year of college, John doesn't have very much money but he really wants a new mp3 player. He ends up shoplifting an mp3 player from a local electronics store.

Once he graduates from college, John has not changed at all. He still has several piercings and often wears his hair in a mohawk. He spends most of his free time at loud punk concerts in basements and other small venues. He plays guitar in a band. His songs feature piercing guitars, screamed vocals, and lyrics about resisting figures of authority.

Four years after graduation, John is the same as he was at the end of college. Whenever he can, he gets together with his bandmates to play punk music. At that time, his friend Alex finds out that John shoplifted an mp3 player when he was a freshman in college. Alex criticizes John severely for his action, and says that he should be ashamed of himself.

Participants then received the same moral criticism question as in Study 2. Finally, participants received analogues of the two mediators in Study 2 (with shoplifting an mp3 player substituted for drunk driving) in counterbalanced order.

\section{Results}

The mean responses to the moral criticism question, the connectedness question, and the deterrence question appear in Figure 10.5: 


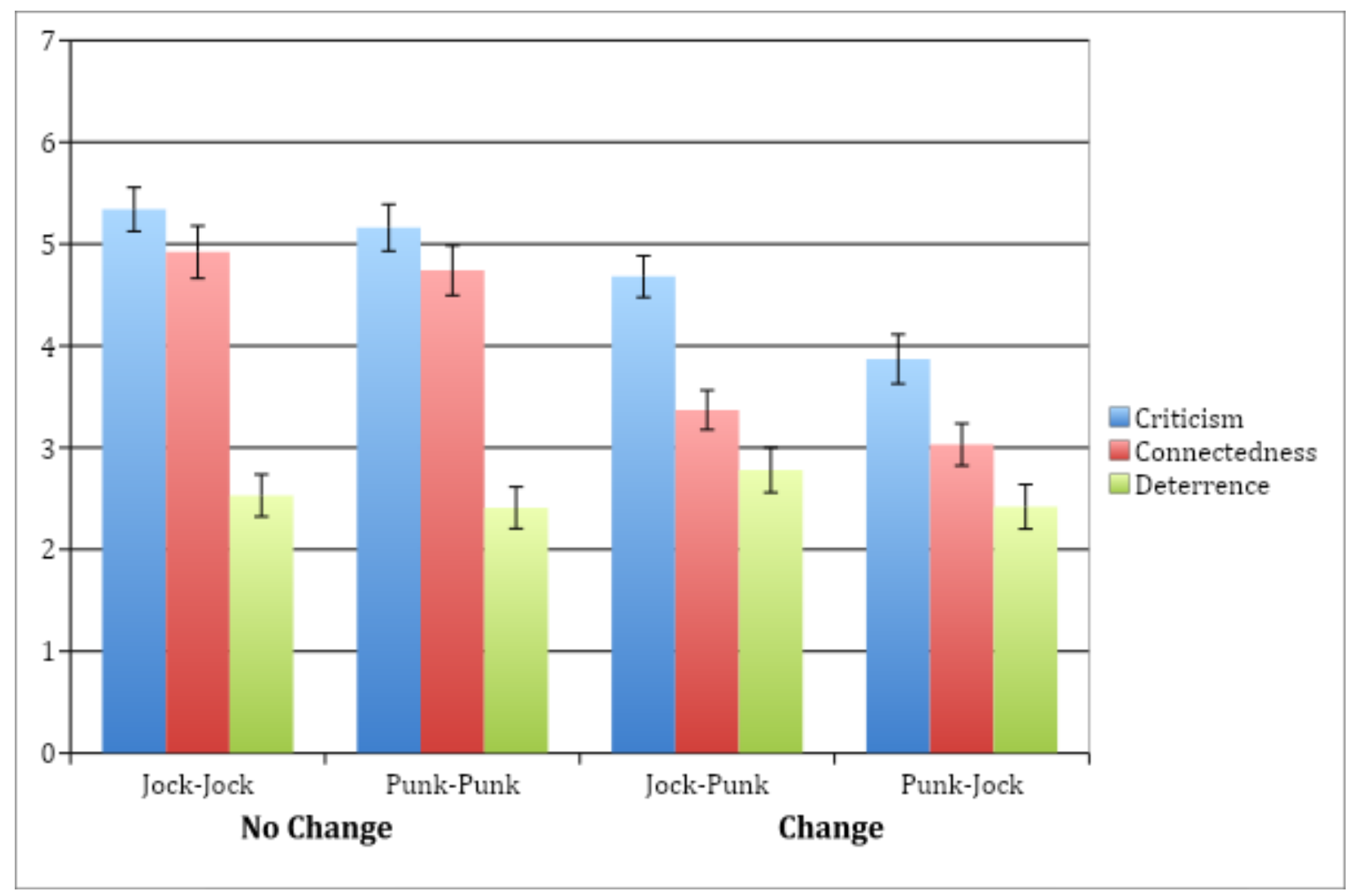

Figure 10.5. Mean ratings for moral criticism, connectedness, and deterrence judgments in Study 3.

A 2 (start punk vs. start jock) x 2 (end punk vs. end jock) ANOVA showed a significant effect of change in character (the interaction) on moral criticism judgments, $F(1,244)=18.97, p<.001$. There was also a significant effect of change in character on connectedness judgments, $F(1,243)$ $=51.11, p<.01$. Change in character did not have a significant effect on deterrence judgments, $F(1,243)=0.38, p=.54$. In addition, a bootstrap mediational analysis (Hayes, 2013) showed a significant indirect effect of change in character on moral criticism judgments through connectedness judgments ( $95 \%$ CIs $[0.14,0.40])$ but not through deterrence judgments $(95 \% \mathrm{CIs}$ $[-0.07,0.03]$ ) (see Figure 10.6). 


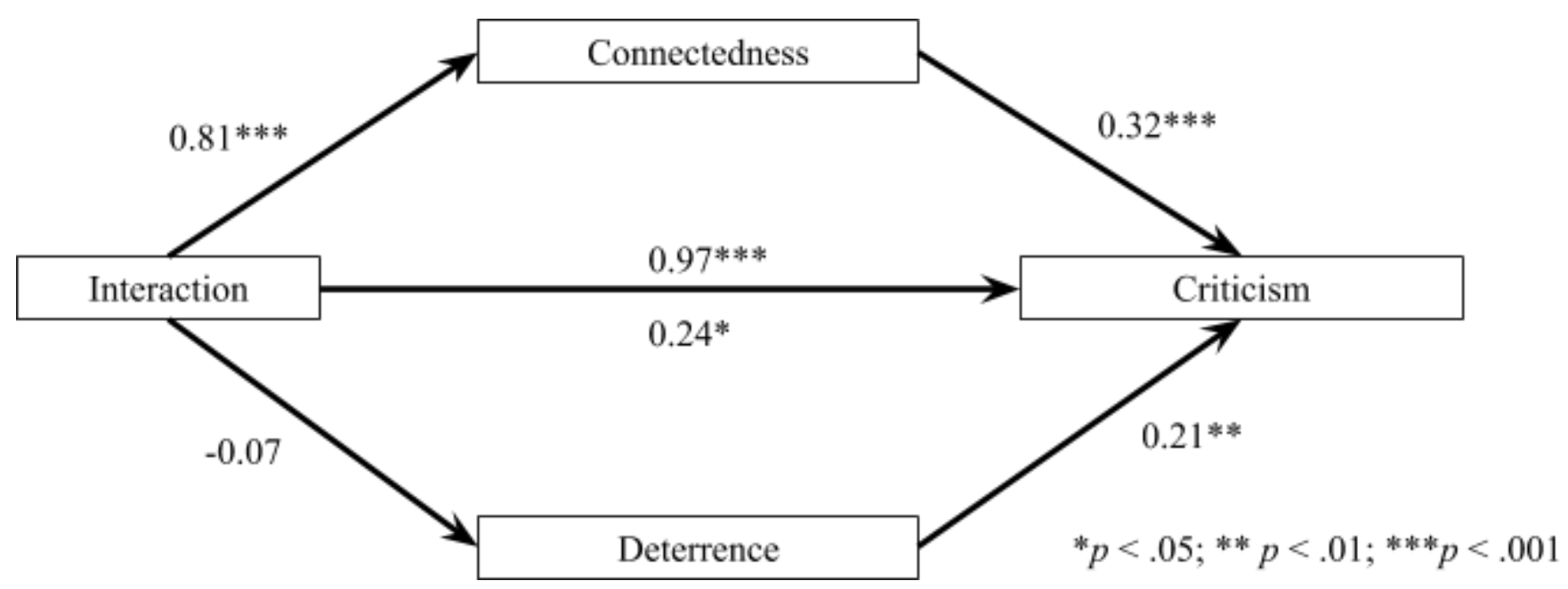

Figure 10.6. Partial mediation of moral criticism judgments by connectedness judgments in Study 3 .

\section{Discussion}

This study demonstrated that a change in a factor that does not appear relevant, prima facie, to moral responsibility could still affect participants' moral judgments by affecting their judgments about connectedness. It also provides some insight into the ordinary concept of connectedness employed by the participants. Since the amount of time between the offense and the moral assessment is the same between conditions, this study rules out certain plausible concepts of connectedness that are closely tied to time. For instance, if one thought the ordinary concept of connectedness was based entirely on memory, one might think that explained the effect in the first two studies when combined with assumptions about the degradation of memory over time. Such an explanation is much less plausible in this case. This result is thus consistent with other recent research that has demonstrated that moral traits are particularly central to the ordinary concept of personal identity (Strohminger \& Nichols 2014).

A character-based concept of connectedness is still consistent with the Parfitian hypothesis. While Parfit's brief discussion of statutes of limitations focused on time, he also recognized that sharp changes in character could affect connectedness. This study does suggest, however, that memory may play even less of a role in ordinary judgments of connectedness than it did in Parfit's theory.

\section{Study 4. Manipulation of connectedness judgments affects legal punishment judgments}

Study 4 aimed to replicate Study 3 using legal punishment judgments rather than moral criticism judgments. This replication was attempted because, despite the results of Study 3, it may still appear implausible that people's judgments about the appropriateness of legal punishment would be affected by something as minor as a change in social circles. ${ }^{22}$

\section{Procedure}

Two hundred forty-two participants were recruited using Amazon's Mechanical Turk. Participants were randomly assigned to read one of four vignettes almost exactly the same as those in Study 3, except that the last two sentences were changed to read:

\footnotetext{
${ }^{22}$ It did to the author.
} 
At that time, the police find a security camera video showing John shoplifting the mp3 player and are able to identify him with $100 \%$ accuracy. They arrest him and turn the video over to the local district attorney.

Participants then received the same legal punishment question as in Study 2. Finally, participants received analogues of the two mediators in Study 2 (with shoplifting an mp3 player substituted for drunk driving) in counterbalanced order.

\section{Results}

The mean responses to the legal punishment question, the connectedness question, and the deterrence question appear in Figure 10.7:

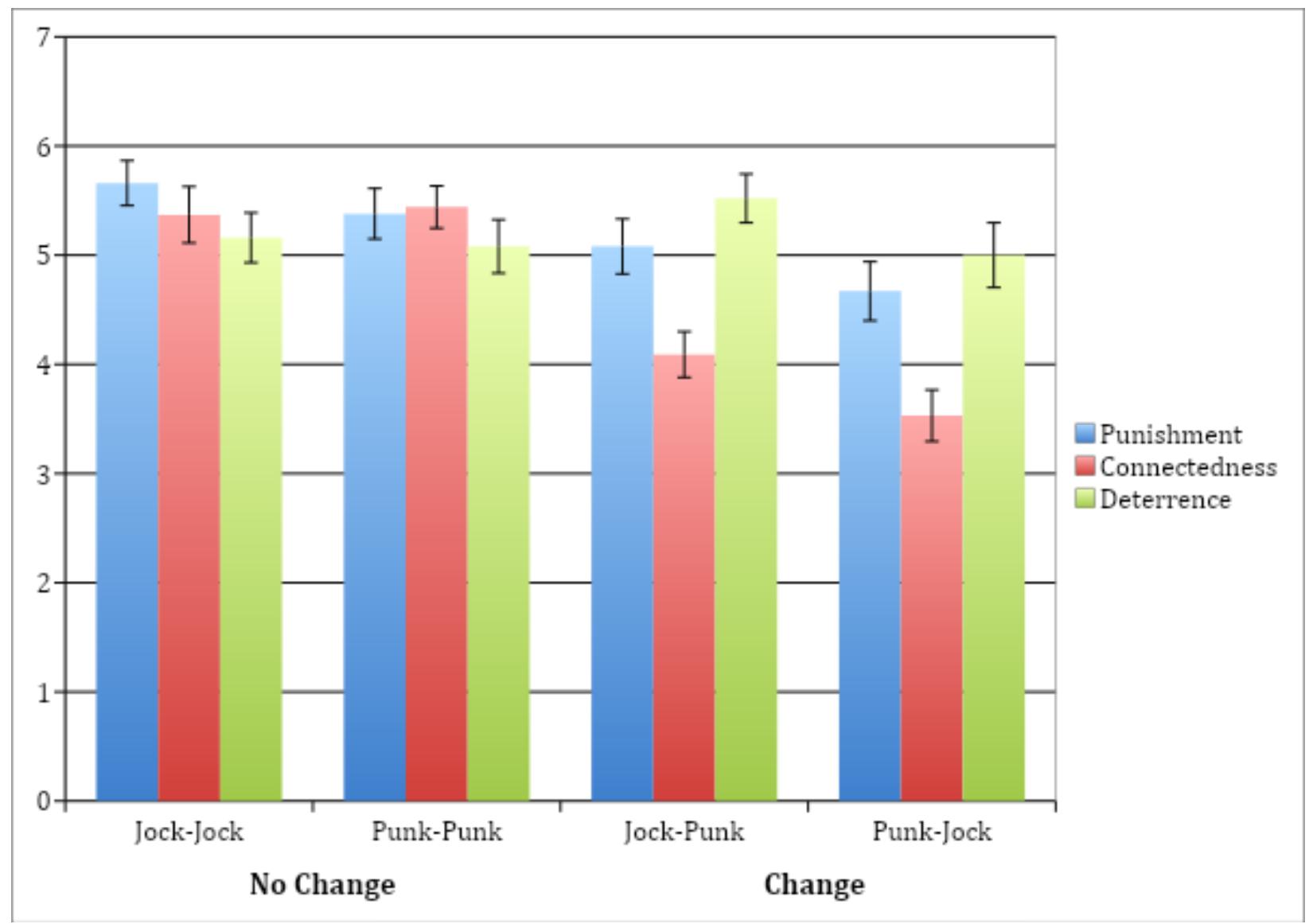

Figure 10.7. Mean ratings for legal punishment, connectedness, and deterrence judgments in Study 4.

A 2 (start punk vs. start jock) x 2 (end punk vs. end jock) ANOVA showed a significant effect of change in character (the interaction) on legal punishment judgments, $F(1,241)=7.10, p<.01$. There was also a significant effect of change in character on connectedness judgments, $F(1,241)$ $=50.88, p<.001$. Change in character did not have a significant effect on deterrence judgments, $F(1,241)=0.32, p=.57$. In addition, a bootstrap mediational analysis (Hayes, 2013) showed full 
mediation of the effect of change in character on legal punishment judgments through connectedness judgments ( $95 \%$ CIs $[0.21,0.53])$ and no mediation by deterrence judgments (95\% CIs [-0.06, 0.01]) (see Figure 10.8).

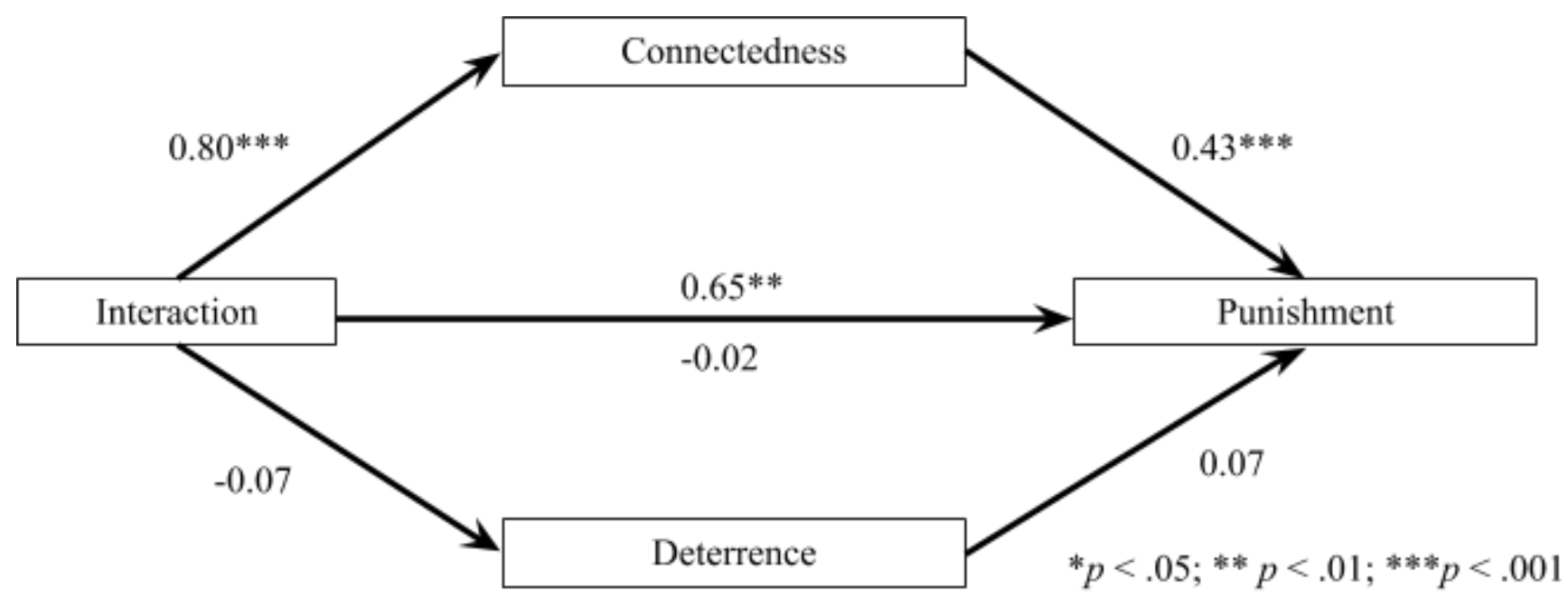

Figure 10.8. Full mediation of legal punishment judgments by connectedness judgments in Study 4.

\section{Discussion}

This study replicated the findings of Study 3 in a legal context. These results reinforce the conclusion, reached after Study 2, that connectedness judgments link moral and legal assessments together.

\section{Study 5. Manipulation of connectedness judgments affects legal punishment judgments (replication and extension)}

Study 5 is almost an exact replication of Study 4, but with a different proposed mediator substituted for deterrence. This mediator assessed whether participants assumed that John was improving over time, so that the analyses could control for the effect of judgments about the valence of particular changes. That is, if all the participants interpreted any change as an improvement, their judgments about punishment might be driven by views on rehabilitation rather than connectedness.

\section{Procedure}

Two hundred forty-nine participants were recruited using Amazon's Mechanical Turk. Participants were randomly assigned to read one of four vignettes used in Study 4. Participants then received the same legal punishment question as in Study 4. Finally, participants received either the connectedness mediator from Study 4 or a new valence mediator, in counterbalanced order. Responses to the valence mediator were given on a seven-point scale from "completely disagree" to "completely agree." It read:

Please indicate the extent to which you agree or disagree with the following statement:

When John is arrested, he is a better person than he was when he shoplifted the mp3 player. 


\section{Results}

The mean responses to the legal punishment question, the connectedness question, and the valence question appear in Figure 10.9:

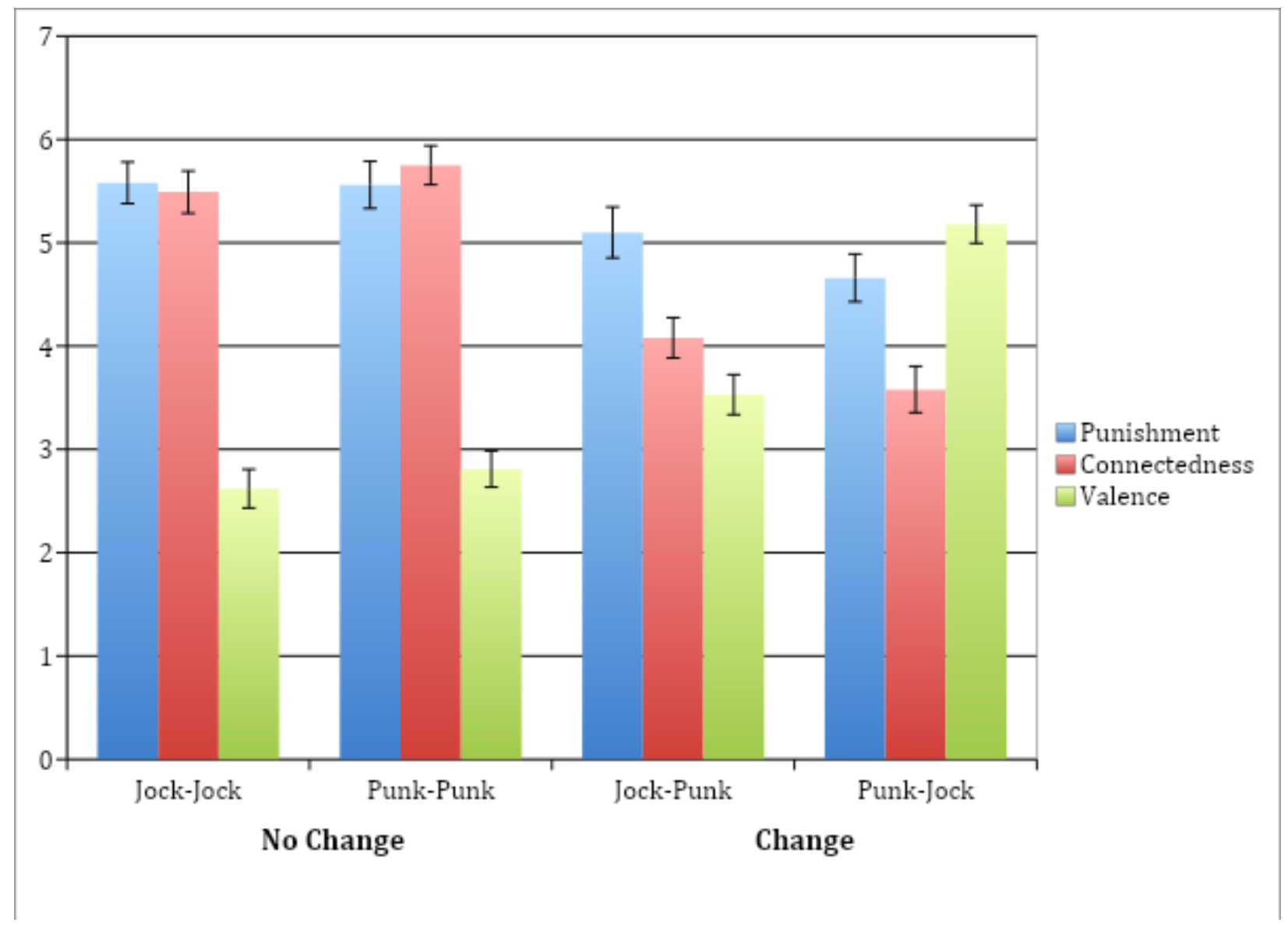

Figure 10.9. Mean ratings for legal punishment, connectedness, and valence judgments in Study 5 .

A 2 (start: punk vs. jock) x 2 (end: punk vs. jock) ANOVA showed a significant effect of change in character (the interaction) on punishment judgments, $F(1,248)=9.3, p<.01$, on connectedness judgments, $F(1,248)=75.8, p<.001$, and on valence judgments $F(1,248)=$ $78.4, p<.001$. A bootstrap mediational analysis (Hayes, 2013) showed full mediation of the effect of the interaction on legal punishment judgments through connectedness judgments $(95 \%$ CIs $[0.11,0.44])$ and no mediation by valence judgments (95\% CIs $[-0.11,0.16])$ (see Figure 10.10). 


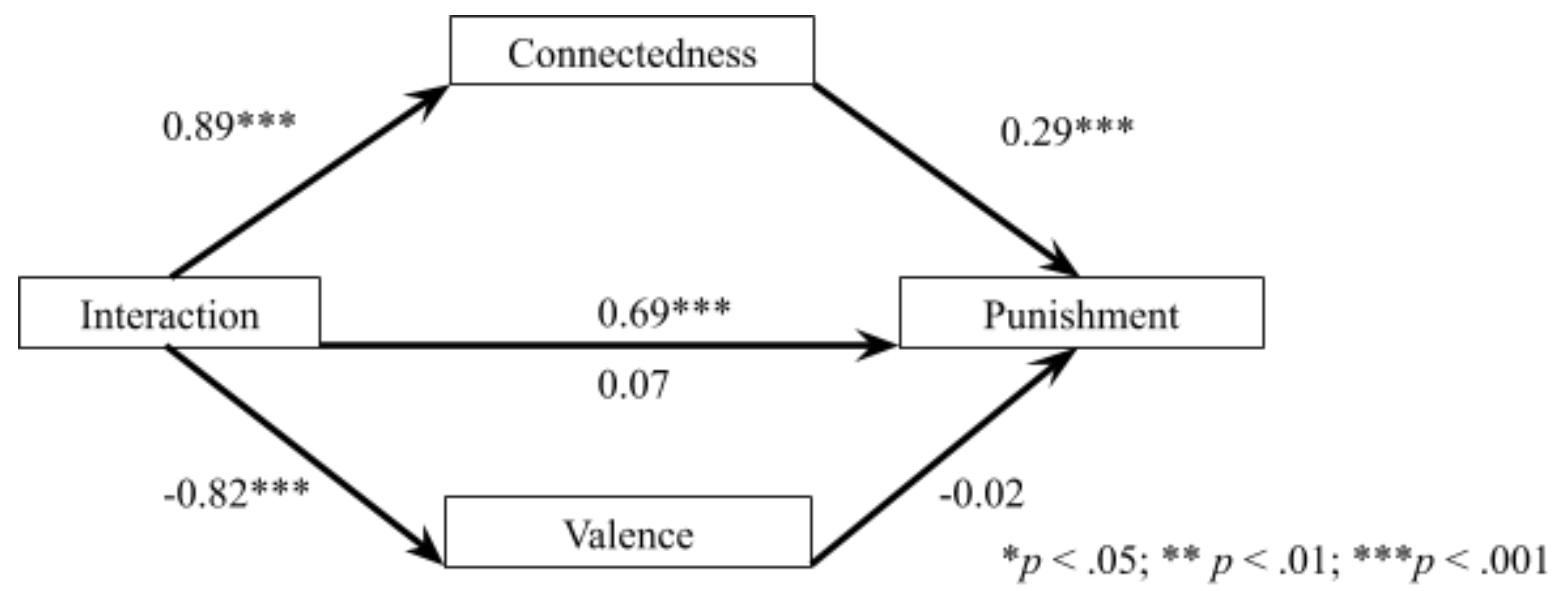

Figure 10.10. Full mediation of legal punishment judgments by connectedness judgments in Study 5.

\section{Discussion}

These results demonstrate that even though participants do not see the change described in both change vignettes as morally neutral, this fact does not drive the effect observed in Study 4. Participants view the change from punk to jock as a moral improvement, while they do not feel the same way about the change from jock to punk. Nevertheless, judgments about valence do not mediate the effect of change in character on judgments about the appropriateness of legal punishment, while judgments about connectedness still do.

The valence measure used in this experiment was limited in an important respect, which may have affected the results. The measure asked participants to indicate whether they agreed with the statement that John had improved. It did not give them the option of indicating that they thought he had degraded. Thus, the means in the two non-change conditions are very low, as the participants, appropriately, did not think John had improved. However, in the two change conditions, participants who thought John had not changed might have given the same answer as participants who thought he had changed for the worse, as both would disagree with the question asked. A valence measure that gave participants the ability to indicate whether they thought John had degraded, stayed the same, or improved may have produced different results. ${ }^{23}$ However, this explanation is unlikely for two reasons. First, a regression using starting character, ending character, change in character, connectedness, and valence to predict punishment judgments showed only one significant effect: the effect of connectedness; $\beta=0.29$, $p<.001$. Valence did not remotely approach significance; $\beta=-0.02, p=0.84$. If valence judgments do mediate the effect, even this flawed measure should reflect that to some extent. Second, very few participants were at floor in the conditions where John did change in character, and markedly more were at floor in the conditions where he did not. ${ }^{24}$ Thus, participants had the ability to express more negative attitudes towards his change in the change condition.

\footnotetext{
${ }^{23}$ This point is due to a reviewer.

${ }^{24}$ Looking at the conditions where he did change, only 6 participants responded "completely disagree" to the valence mediator in the Jock-to-Punk condition, as compared to 2 participants who did so in the Punk-to-Jock condition. Looking at the conditions where he did not change, 11 participants responded "completely disagree" to the valence mediator in the Punk-to-Punk condition, as compared to 21 in the Jock-to-Jock condition.
} 


\section{General Discussion}

These studies support the hypotheses that both legal and moral statutes of limitations are intuitive and that judgments about the connectedness of the self play a significant role in these intuitions. These findings fit neatly into the line of research showing that judgments about connectedness of the self can affect participants' judgments about reward and punishment. The studies also provide suggestive evidence that judgments about deterrence and a right to repose play some role in intuitions about statutes of limitations. Further research will be necessary to determine the exact nature of this role, and the relationships between these concepts and the concept of connectedness of the self.

The studies also provide insight into what sort of changes people think have an effect on the connectedness of the self. The existing research on connectedness has involved directly and explicitly manipulating these judgments by telling participants that, for instance, there are large or small changes to the self during college (Bartels, Kvaran, \& Nicols, 2013). The present studies, by contrast, manipulated connectedness indirectly, by adjusting the amount of time that has passed since an incident (Studies 1-2) or the social affiliation of the vignette's protagonist (Studies 3-5). Thus, while the existing literature made it clear that changes in judgments about connectedness can have significant effects on behavior, these studies demonstrate that commonplace factors - the passage of time, changes in a person's social circles - have an effect on connectedness judgments.

These results do not decide the normative question about whether and why statutes of limitations are justified. They do, however, bear on the normative debate. They suggest that statutes of limitations persist, at least in part, because they are psychologically intuitive, and that part of the reason they are psychologically intuitive is because of views about how time affects the degree to which people are connected to their past selves. To the extent that the laws creating statutes of limitations have democratic support, ${ }^{25}$ it may be due to this intuitive pull. Thus, it would be a mistake for legal theorists to ignore metaphysical views about connectedness when considering how to justify statutes of limitations.

I should note, however, that there are aspects of statutes of limitations, as they actually exist in the world, that would be counterintuitive according to these results. First, in almost every state, the statute of limitations on a crime is tolled - that is, paused - when the defendant is outside the jurisdiction. So, for instance, an individual who commits robbery in Massachusetts, evades capture, flees to New York, and starts a life there, may be arrested as soon as he sets foot back in Massachusetts, no matter how long he was out of the jurisdiction. Some states have laws that end the tolling after a certain number of years but, nevertheless, the actual rules display a complexity that the present studies have not captured. If these tolling rules are intuitive, these intuitions almost certainly arise from some other source than judgments about personal identity over time. ${ }^{26}$ Second, one would expect that if statutes of limitations are intuitive, they would exist in every jurisdiction in a fairly similar form. It turns out this is not true. In a small minority of states, the statute of limitations on a crime only starts running when the crime is discovered. ${ }^{27}$ If these rules are intuitive, these intuitions would be in tension with judgments of personal identity over time.

\footnotetext{
25 Though I would imagine there haven't been very many polls on this question.

${ }^{26}$ A fairly obvious candidate for the source of these intuitions is the feeling that criminals should not be able to avoid punishment simply by fleeing and staying away until the limitations period has run.

${ }^{27}$ There are similar, crime-specific rules in other jurisdictions. For instance, in Massachusetts, the statute of limitations on sex offenses only starts running when the victim has reached 16 (see Mass. Gen. Laws chapter 277 , section 63). The intuitive appeal of these types of exceptions is also obvious.
} 
There are also a number of significant limitations to the present studies. I will mention three that are particularly apparent.

First, while Study 5 attempted to disambiguate judgments of connectedness from judgments of valence - and, by extension, judgments about rehabilitation - it could only do so in a limited sense. The changes described in the vignettes used in that study were minor. While participants interpreted them to have a particular valence, it is reasonable to assume that they did not see the change from punk to jock as a particularly dramatic improvement. Thus, the study cannot speak to whether, in cases of more marked improvement or degradation, the effect of connectedness would predominate. It is possible that participants' desire to reward those who improve and to punish those who degrade would overwhelm this effect. It is also possible that larger improvements or degradations would affect judgments of connectedness in ways that this study did not capture. Further research will be necessary to determine the relative strengths of judgments about connectedness and judgments about valence, and to determine more decisively whether assumptions about the likelihood of improvement over time also played some role in the time-based effect observed in Studies 1 and 2.

Second, these results are in some tension with the results of Tobia (2015). If personal identity and connectedness are correlated concepts, his findings indicate that ordinary people would view a person who had improved over time as more connected to a past self that had engaged in wrongdoing than they would a person who had degraded. The present findings would then imply that a person who improved would be more appropriately criticized and punished than a person who degraded, and that both would be less appropriately criticized than someone who had not changed at all. Although one cannot know with certainty from the armchair, such a finding would be shocking. Fortunately, several possible avenues of research could provide a way out of this conundrum. First, as suggested above, the desire to reward individuals for improving and to punish them for degrading might overwhelm either effect. Second, it may be that the ordinary concept of connectedness and the ordinary concept of personal identity are not correlated in the way this implausible argument assumes or that, as Tobia suggested, legal identity is distinct from personal identity. Third, and most plausibly, it may be that connectedness judgments vary for different types of changes. For instance, it is plausible that in cases of explicitly moral change, connectedness judgments do not depend purely on the fact of change (as they did in Study 5) but also on the nature of the change. When a past instance of wrongdoing is seen as evidence of a person's true character (because the person subsequently degraded) participants may draw conclusions about connectedness that they would not when the wrongdoing seems like an anomaly (because the person subsequently improved). This hypothesis is consistent with recent research on the true self (De Freitas, Tobia, Newman, \& Knobe 2016; Newman, De Freitas, \& Knobe 2015; Tobia 2016).

Third, the crimes described in these vignettes were all fairly minor - drunk driving without causing injury or shoplifting an mp3 player. Minor crimes were used so that judgments about restitution and victim's rights would not confound the analysis. Furthermore, particularly serious crimes - like murder and rape and acts of terrorism - might be viewed as identity-defining in a way that would overwhelm the modest effect of time or changing social circles. Further research will be necessary to investigate the effect on these factors on judgments about the appropriateness of legal and moral punishment over time. 


\section{References}

Bartels, D., Kvaran, T., \& Nichols, S. (2013) Selfless giving. Cognition 129, 392-403.

De Freitas, J. Tobia, K., Newman, G., and Knobe, J. (2016). Normative judgments and individual essence. Cognitive Science.

Glannon, W. (1998) Moral responsibility and personal identity. American Philosophical Quarterly 35, 231-249.

Hayes, A.F. (2013) Introduction to Mediation, Moderation, and Conditional Process Analysis. Guildford Press.

Khoury, A.C. (2013) Synchronic and diachronic responsibility. Philosophical Studies 165, 735-752.

Listokin, Y. (2002) Efficient time bars: A new rationale for the existence of statutes of limitations in criminal law. Journal of Legal Studies 31, 99-118.

Newman, G.E., De Freitas, J., and Knobe, J. (2015). Beliefs about the true self explain asymmetries based on moral judgment. Cognitive Science 39, 96-125.

Ochoa, T. \& Wistrich, A. (1997) The puzzling purposes of statutes of limitation. Pacific Law Journal 28, 453-514.

Parfit, D. (1984) Reasons and Persons, Oxford.

Powell, L. (2008) Unraveling criminal statutes of limitations, American Criminal Law Review $45,115-154$.

Robinson, P. (1982) Criminal law defenses: A systematic analysis, Columbia Law Review 82, 199-291.

Shoemaker, D. (2012) Responsibility without identity, Harvard Review of Philosophy 18, 109-132.

Skolnick, J. (2011) Justice Without Trial: Law Enforcement in Democratic Society, Quid Pro Books.

Strohminger, N. \& Nichols, S. (2014). The essential moral self. Cognition 131, 159-171.

Tierney, H., Howard, C., Kumar, V., Kvaran, T., \& Nichols, S. (2014) How many of us are there? In Advances in Experimental Philosophy of Mind, ed. J. Sytsma. Bloomsbury Press:181-202.

Tobia, K. P. (2015). Personal identity and the Phineas Gage effect. Analysis, 75, 396-405.

Tobia, K. P. (2016). Personal identity, direction of change, and neuroethics. Neuroethics, 9 , $37-43$. 